\title{
INNOVATION AND SHORTAGE: THE YIN AND YANG OF THE HEALTH SECTOR*
}

\author{
Karen EGGLESTON
}

The economic challenges countries face when adopting personalized medicine technologies provide an important illustration of many of the concepts articulated by János Kornai in his pioneering research on innovation in market-driven, capitalist surplus economies. In Chinese philosophy, Yin and Yang often represent contradictory yet inseparable opposites - two forces that not merely coexist, but are synergistic and mutually dependent. This concept is an apt analogy for the relationship between innovation and shortage in the health sector. Dangers arise from over-emphasizing the Yin of innovation over the Yang of access, and vice versa. If we over-constrain innovation, we die needlessly early and forfeit quality of life that innovations might have enabled. If we do not distribute access to innovations equitably, we diminish our humanity, suffer backlashes from populism and distrust of science and expertise, and risk social instability, even violent conflict.

Keywords: health sector, personalized medicine, innovation, health technologies

JEL classification indices: H51, H570, I0

* This paper is dedicated to Professor János KORNAI, an inspiring intellect and mentor, who will turn 90 years old on January 21, 2018. I am grateful to Péter Mihályi for his kind invitation to contribute to this special issue of Acta Oeconomica in honor of János, and to Ross Eric Johnson and Hokuto Asano for excellent research assistance.

Karen Eggleston, Professor at Stanford University and National Bureau of Economic Research, Director of the Asia Health Policy Program. E-mail: karene@stanford.edu 


\section{INTRODUCTION}

The economic challenges countries face when adopting (or failing to adopt) personalized medicine technologies provide an important illustration of many of the concepts articulated by János Kornai in his pioneering research on innovation and surplus economies. This paper makes the case that in the $21^{\text {st }}$ century, surplus economies will increasingly face the challenge of innovating to address "shortage within surplus" in a vital sector of the economy - that of health and medical care. This sector is growing as a share of the economy in virtually all countries, and the dilemmas of balancing innovation for longevity with solidarity in distribution will be exacerbated by genomic and proteomic "precision and personalized medicine" (PPM) breakthroughs. The narrative draws from my joint work with Kornai on choice and solidarity in the health sector (Kornai - Eggleston 2001; Kornai 2013; Eggleston 2016).

In Chinese philosophy, Yin and Yang often represent contradictory yet inseparable opposites - two forces that not merely co-exist, but are synergistic and mutually dependent. This concept is an apt analogy for the relationship between innovation and shortage in the health sector. ${ }^{1}$

For those focused on the macroeconomics of comparative economic systems and Kornai's contributions regarding shortage versus surplus economies (e.g., Xu 2017), this paper makes the case that the health sector provides a microcosm that perpetuates within a surplus economy the many features of a shortage economy, with close approximations of the many phenomena of chronic shortage he has analyzed: non-price coordination mechanisms, queuing, forced substitution, high employment even during recessions, high prevalence of government and not-forprofit ownership, and difficulty in assessing and rewarding efficiency, productivity, and value-added from a societal perspective, to name but a few. Perhaps ironically, given the value of health and longevity, the experience of shortage is not vanquished by the dominance of capitalism in almost all corners of the globe. Kornai's insights about the mechanisms and coping strategies under shortage will remain relevant indefinitely in our economic future, for understanding how innovation and shortage interact in the health sector.

For my fellow health economists, this paper introduces and makes the case for the relevance of Kornai's writings for understanding comparative health systems - subsectors within capitalist economies that manifest the phenomena of shortage. While we health economists often attribute these characteristics of shortage

Yin and Yang are an especially apt analogy for innovation and shortage for a health economist who first read Kornai's works in Mandarin while studying in China to understand the economics of transition. 
solely to their microeconomic roots and assume they are divorced from the field of comparative economic systems, our understanding can actually be enriched by a comparative economic systems perspective. ${ }^{2}$

The paper first discusses the concepts of innovation and shortage, underscoring Kornai's important research in these two spheres, and then turns to their interaction in the health sector. Specific examples from personalized medicine represent the leitmotif of this theme that innovation and shortage are and will continue to be inextricably intertwined in health systems of low- and high-income countries alike.

\section{INNOVATION AND SHORTAGE}

Innovation and its determinants form the centerpiece of Dynamism, Rivalry, and the Surplus Economy by János Kornai, a significant contribution to our understanding of the two great economic systems, socialism and capitalism. While the book focuses on capitalism, arguably its primary contribution lies in the emphasis on those vital aspects of capitalism that only juxtaposition with socialism can fully bring to light: innovation and surplus. He argues compellingly that innovation is one of the great virtues of capitalism, through Schumpeterian "creative destruction", and that socialism is incapable of producing sustained innovation in any sector of the economy, as illustrated by all the great innovations of the past 100 years taking place in capitalist systems. He also makes thought-provoking and apt references to evolutionary biology and behavioral economics, topics not often associated with comparative economic systems and economic history.

Kornai (2013) argues that only capitalism can continually sustain a surplus economy encompassing the whole economy, noting several exceptions "that prove the rule" such as military technology for socialist regimes' survival, or the rationing of healthcare within otherwise surplus economies. It is the latter topic, which he and I have collaboratively researched previously, that this essay explores in greater detail. I argue that this island of shortage within surplus will grow not only in terms of the share of the economy (and thus the opportunity costs of the resources it absorbs), but also in the social salience of dilemmas in balancing innovation with access in the era of precision health and personalized therapies.

2 Moreover, this similarity of health sectors with shortage economies, unless carefully understood for its linkage to surplus and innovation, might exacerbate the tendency of some - especially in the US - to decry "socialized medicine". To the contrary, organized financing with embedded income solidarity and risk solidarity is integral to enabling our society to sustain a stream of health technology innovations that improve our well-being and longevity. 
Shortage characterizes centrally-planned economies. Lack of innovation is both the cause and result of this phenomenon of socialism systems: "The shortage economy, one of the strongest system-specific properties of socialism, paralyzes the forceful engine of innovation, the incentive to fight for the favors of the customer.... The producer/seller is not compelled to attract the buyer by offering him a new and better product [or service], since the latter is happy to get anything..., even an obsolete and poor-quality product [or service]" (Kornai 2013: 15).

However, shortage can appear in specific sub-sectors of capitalist economies as well; indeed, "phenomena of shortage appear universally in the allocation and utilization of free or almost-free public services" (Kornai 2013: 125). Health economists will recognize the concept of moral hazard, how health systems cope with the imbalance of supply and demand, and the "dynamic moral hazard" from insurance coverage that spurs innovations.

To the extent that shortage is inextricably linked to the social impulse to provide equitable access and solidarity in life chances, this phenomenon has its bright side. As emphasized in the literature on the origins of inequality, opportunities for education and self-fulfillment depend on a child's luck of birth in a poor or rich country (Deaton 2013); and those born into socialist regimes during the $20^{\text {th }}$ century usually benefited from the enhanced access to basic health technologies that such systems promoted:

"The socialist state's paternalist pricing policy and financing of the welfare sectors exert equalizing effects, which ultimately involve a redistribution of incomes. Practically everybody is entitled in a shortage economy to free public education and free health care, including poorer strata that would not be able to pay their cost in a 'pure' market economy" (Kornai 2013: 112).

Indeed, East Germany's life expectancy at the lowest quintile exceeded that of West Germany for much of its existence; and China's largest increases in life expectancy occurred under the Mao-era socialist system, from what might be called innovation born of necessity: promoting primary care through barefoot doctors and emphasizing low-cost population health measures as well as basic education (Babiarz et al. 2015).

Numerous measures that substantially enhanced the length and quality of life in otherwise especially resource-constrained economies included population health campaigns and addressing basic social determinants of health for the vulnerable segments of the population such as sanitation, clean water, decent housing, widespread immunization, employment, and food security, as well as access to basic health services and medications such as antibiotics. In some instances, technological breakthroughs also took place under socialism. For example, artemisinin combination therapy is the standard combination therapy for one of 
the worst global killers, malaria, and derives from a traditional Chinese medicine treatment. Artemisinin (青蒿素, Qinghaosu) treatment for malaria was discovered (1972) and manufactured (1979) as part of a military project initiated under Mao Zedong's government (project 523) in China; in 2009, it was approved by the US Food and Drug Administration and earned discoverer Youyou Tu first the prestigious Lasker-DeBakey Clinical Medical Research Award, and then the Nobel Prize in Physiology or Medicine in 2015.

However, as will be discussed below, this example may be the exception that proves the rule that Kornai argued, the lack of a socio-economic context for breakthrough technological innovations and their marketization in economies characterized by general shortage. It is also important to acknowledge the limits to our knowledge about how best to promote institutional innovation. Necessity may be the mother of invention, but invention does not always spring to life whenever it appears to be a necessity, as the premature mortality throughout the low-income world attests. Moreover, the institutional innovation that socialist countries were adept at promoting - low-cost population health measures relying on individuals to comply with centralized orders - do not appear to be the most salient for breakthroughs in health in the $21^{\text {st }}$ century. Societies are still struggling with how best to promote individual healthy behavior, and post-socialist economies have not been any more effective than traditionally capitalist ones - indeed, in many cases considerably less successful - e.g., in convincing individuals to quit smoking, stop excessive drinking, eat healthily, and avoid sedentary lifestyles that lead to premature mortality. Moreover, while substantial health gains could follow from such simple measures as consistent use of seatbelts and bicycle/motorcycle helmets, ${ }^{3}$ the technological innovations extending life in the $21^{\text {st }}$ century may derive more from personalized therapies for cancer and cardiovascular disease, rather than low-cost public health measures pioneered in shortage economies.

\section{INNOVATION AND SHORTAGE: YIN AND YANG IN THE HEALTH SECTOR}

The health sector is everywhere shaped by the dynamic interaction of innovation and shortage, while dealing with numerous market failures in healthcare financing and delivery (Arrow 1963). The seemingly inexorable increases in healthcare spending are driven by innovations: "The rate of health care spending growth cannot exceed income growth indefinitely ... eventually we will need to develop a

Ironically, a physician in China is more likely to wear a helmet while working in a hospital than while biking, given the toxic doctor-patient relations that have resulted in violent attacks on healthcare workers. 
financing system that is sustainable in the long run. Such a system will inherently alter the process by which new innovation moves into medical practice" (Chernew - Newhouse 2012: 37). Precision health technologies, given their often steep prices, presage exacerbation of this challenge of ballooning health system expenditures.

The health sector also underscores the moral challenges presented by innovation and shortage. One of the cruelest manifestations of shortage is the allocation of life-saving technologies only to those who can afford them - and providing economic incentive for innovation focusing on diseases that afflict the rich exclusively, or more than, the poor (Eggleston 2016). The starting point in Kornai and Eggleston (2001) is the ethical challenge of promoting individual sovereignty and choice on the one hand, while assuring social solidarity, i.e., helping the suffering, the troubled, and the disadvantaged on the other. These two ethical principles have their counterparts in the phenomena of innovation and shortage (or access): can a health system sustain both choices (i.e., allowing the wealthy to purchase health improvements, not just flat-screen TVs) and solidarity to provide access to those same health improvements for those less fortunate, or at least for what is considered "basic" healthcare? Deaton $(2003,2013)$ emphasizes a similar point: innovations, first in population health and later in medical care, raised inequality but also brought progress with "trickle down" access for the poor. Certainly, a child born today in the poorest country on earth still has a higher potential to live a long healthy life than the richest individuals born over a century ago. This is true because science, population health, and economic development, even if uneven, have expanded the possibilities for all; social policies determine how soon and how completely those same possibilities for healthy longevity are made available to those less fortunate.

The mechanism underlying the "island of shortage" in the health sector bears many similarities to the classic shortage economy symptoms that Kornai has so eloquently and thoroughly dissected.

"Most of the economic environment operates as a surplus economy, with all its usual side effects, but, in the sea of surplus, an island that bears the marks of a shortage economy can be seen. The doctor's office is crowded and you may have to wait for hours. The waiting lists for surgery or diagnostic procedure may be months long (Kornai 2013: Table 7.1). Patients' freedom is severely restricted in choosing a doctor or a hospital. In fact there are health-care systems that deny patients such freedom entirely, so that they have to accept the assigned doctor or health institution. The concept of forced substitution can also apply in medical care, where patients may not obtain the medicine, treatment, or physician they would choose and have to take what they are allocated" (Kornai 2013: 125). 
Such forced substitution may become ever more acute as some patients enjoy access to expensive new personalized medical therapies, while others must make do with older standards of care that eventually will not even qualify as "basic".

But the shortage that drives the healthcare spending conundrum differs from the generalized shortage under a centrally planned economy. Its effects are similar, but its causes are distinct. Socialist shortage arises without, and indeed stifles, innovation; health sector shortage arises because of innovation.

Innovation and shortage are causally and inextricably intertwined in the health sector, representing a Yin and Yang cycle: shortage spurs innovation, innovation breeds shortage, which in turn already provides the seeds of new innovations. Whether ultimately this is a virtuous or vicious cycle depends on the wisdom of policy choices.

To be more specific, the high price of new therapies and devices exacerbates shortage, but can also serve to prod the same or other innovators to search for lower-cost ways of producing and delivering the innovations, as well as pressure for policy innovations to support access. Egalitarian distribution blunts incentives for innovation by reducing the rewards innovators can charge high willingnessto-pay consumers; however, the commitment to egalitarian distribution in the health sector also encourages innovation because it (1) reassures innovating firms that their products will have a ready market (eventually), rather than be permanently relegated to the niche market of only the richest population; and (2) spurs cost-reducing innovations in new technologies. One fascinating example of the latter is the foldable microscope invented by Prakash and colleagues at Stanford, an extremely low-cost technology for accurate diagnosis in even the most remote and resource-constrained parts of the world. ${ }^{4}$ Many other examples could be cited. Such solidarity-inspired innovation - to reduce costs and support broad access - alleviates shortage, but may also blunt incentives for future innovations, depending on policy design.

Thus, the shortage manifest within health systems, particularly in high-income capitalist economies but throughout the world to greater or lesser extent, is itself a product of surplus. It is only because the economy - in the same country or elsewhere on the globe - is constantly producing breakthrough technologies for health and medical care that the health policymakers in a given country continually face a dilemma regarding financing access to those innovations. This stream of new health technologies prompts governments to create agencies to evaluate their costs and benefits, a topic we turn to next.

4 See his TED talk at https://www.ted.com/talks/manu_prakash_a_50_cent_microscope_that_ folds_like_origami or read about the technology in Cybulski et al. (2014). 


\section{EVALUATING INNOVATIONS AND MITIGATING SHORTAGE: HEALTH TECHNOLOGY ASSESSMENT AGENCIES}

Given the Yin and Yang of innovation and shortage in the health sector, formal institutions for weighing the benefits and costs of new health interventions and medical technologies have emerged in both low- and high-income countries over the past two decades. Starting with some initial studies and policy decisions in the US, other countries have pioneered in the use of cost-effectiveness for health system decision-making. Most prominent is the UK, with its NICE (now National Institute for Health and Care Excellence) established in 1999. Australia instituted health economic assessment for pharmaceuticals even earlier. Canadian law articulates "resources stewardship" as a principle guiding the health system, and government agencies and/or formal requirements for health technology assessment with cost-effectiveness analyses have been established in Sweden (2002), Germany (2004), France (2005), Netherlands (2005), Poland (2005 Agency for Polish Technology Assessment), South Korea (2006), and in multiple countries in other regions (Gulácsi et al. 2012; Neumann et al. 2017). Although the embrace of health technology assessment in the new member states of Europe lagged behind what many expected in the early years of the transition, Poland and Hungary have been relative early-movers with health technology assessment in Central and Eastern Europe (Gulácsi et al. 2012) and systems there continue to evolve in dealing with significant resource constraints. In Japan, the government decided in 2014 to launch a pilot program for health technology assessment, and by 2017 several pharmaceuticals had been reviewed in this cost-effectiveness appraisal process, including two target therapies, Sovaldi (sofosbuvir) for hepatitis $\mathrm{C}$ and Opdivo (nivolumab) for metastatic non-small cell lung cancer; the expanded assessment program aims to re-price several drugs in 2018 as well as to establish a new government organization for the review of manufacturers' data (Asano 2017; Asia Pacific Observatory Japan HiT 2017). Moreover, prominent organizations in global health, both public and private, have embraced the need for systematic presentation of costs as one input to decision-making for health, as evidenced by the initiatives of the World Health Organization and the Bill and Melinda Gates Foundation (Neumann et al. 2017).

The trend has not been uniformly towards greater acceptance of such institutions. In the US, the Office of Technology Assessment, established in 1972, was abolished by Congress in 1995, just when health technology assessment agencies were being launched in other countries (e.g., Australia adopted pharmacoeconomic guidelines for pharmaceutical benefits coverage in 1993; the Canadian Coordinating Office for Health Technology Assessment published its first guidelines in 1994; and the World Health Organization established a project for guid- 
ing resource allocation considering costs in 1998). In fact, the 2010 Affordable Care Act in the US proscribes use of cost-effectiveness thresholds.

Political and legal controversies have arisen regarding explicit cost criteria in health coverage decisions in other countries besides the US. In Germany, a 2005 court ruling requires the government to reimburse for medical treatment if there is no alternative and the disease is life-threatening (Neumann et al. 2017:12).

Interestingly, the explicit consideration of costs has been less controversial and more widespread for preventive services and health and occupational safety regulation, compared to curative medical therapies. This tendency might not appear surprising in the light of the differences people perceive in allocating resources for saving "statistical lives" versus identified lives (individuals with names facing lifeor-death choices). Even in the US, where the explicit use of cost-effectiveness for medical coverage decisions has been anathema, official agencies used cost-effectiveness analysis in several cases: the 1980 decision for Medicare to cover pneumococcal vaccination; the 1996 Center for Disease Control Community Preventive Services Task Force Guide; and the 2003 Office of Management and Budget requirements for new health and safety regulations (Neumann et al. 2017).

Among medical technologies, the most common and earliest applications have been for pharmaceuticals, as pioneered by Australia a quarter century ago. When a society refuses to use explicit cost-effectiveness analyses, such as in the US for most beneficiaries of public or private insurance coverage, then the function of allocating access falls to price: what co-payments insured patients must pay, or the full prices set for therapies not covered by insurance at all. Pharmaceutical pricing illustrates this dilemma of promoting access (favoring a low, marginalcost price) versus incentives for innovation (favoring a higher, above-averagecost price). Without past innovation, there can be no current access; and pricing for current innovators will determine what access is possible in the future. No pricing policy can achieve both the dynamic efficiency of covering joint sunk costs of research and development and some return on investment, while simultaneously promoting broad access (static efficiency) with prices not much higher than user-specific marginal costs of production. Some policies such as patent protection, generic promotion, and compulsory licensing try to balance the imperatives, mitigating the innovation-inspired shortage.

\section{EXAMPLES FROM PRECISION AND PERSONALIZED MEDICINE (PPM)}

Precision medicine has a range of definitions, but in general refers to tailoring interventions or therapies to an individual's characteristics as assessed by biomarkers, often genetic testing, that predict the individual's response to a specific treat- 
ment. For example, a truly "personalized" treatment recently approved by the FDA in the US was a new gene therapy, CTL019 CAR-T cell therapy for B-cell acute lymphoblastic leukemia, developed by Novartis; but more generally, precision and personalized medicine (PPM) connotes the combination of a therapy with a companion diagnostic test to identify the individuals who would respond to the therapy (Berndt - Trusheim 2017).

Personalized medicine dominates in the newest anti-cancer treatments. It is no coincidence that some of the more recent countries or regions to adopt cost-effectiveness criteria in decision-making have focused on assessment of expensive therapies for cancer, such as Japan's pilot program. New precision medicine technologies such as genomic diagnostic tests and targeted therapies often promise great clinical benefits - substantial gains in survival or even "cures." However, they almost always are extremely expensive. The high price tag raises controversy. For example, Sovaldi (sofosbuvir) for hepatitis C launched in 2013 at a price of $\$ 84,000$ per patient, and Harvoni for $\$ 94,500$, garnering much criticism despite the argument that these cures saved money from liver transplants and other expenses for patients with the disease. The innovators soon lost market share to a competing innovator (AbbVie) offering a course of treatment at substantially lower cost, leading to a new "Bertrand competition" on price (Berndt - Trusheim 2017). This case illustrates both cost-reducing innovation and the risks that innovators face in developing and pricing their products.

The expenditures on target therapies can be quite formidable. In Japan, for example, expenditure of $¥ 180,000$ (\$1636) per month is typical for patients who take one Gefitinib a day for lung cancer, and $¥ 300,000$ (\$2688) a month for patients taking Gleevec for gastrointestinal stromal tumor (Asano 2017: Table 3). Since Japan has a generous stop-loss policy as part of its universal health coverage, it is taxpayers and government budgets, and not patients, who bear the brunt of these costs. Nevertheless, providing solidarity with inclusive coverage of such expensive therapies represents a nontrivial fiscal commitment.

In the face of targeted therapies of significant cost, cost-effectiveness evaluations prior to coverage decisions are bound to expand in many countries. Coverage of life-saving therapies may continue to be given priority over preventive services, even if the latter may in the end prove to be more cost-effective. In other words, in the arena of preventive services, cost-effectiveness criteria are routinely used to limit the budgetary expense associated with new interventions, including potentially expensive genomic testing. For example, Japan's social health insurance program does not cover BRCA1/2 genetic testing for breast cancer (Asano 2017), although genetic testing of tumors and target therapy for breast cancer are routinely covered. 
Patients in Central and Eastern Europe have experienced barriers to access to precision medicine innovations compared to other Europeans, for a variety of budgetary and institutional reasons. A 2016 survey revealed that many patients in lower-income countries of Europe cannot afford anticancer treatments, especially innovative drugs for melanoma, renal cell cancer, and colorectal cancer (Mayor 2016).

One of the earliest and most well-known examples of PPM is Herceptin (trastuzumab) for breast cancer. This breakthrough treatment for human epidermal growth factor receptor type 2 (HER2)-positive breast cancer - first for metastatic cancer, and later expanded to earlier stage HER2-positive breast cancer - has transformed prognosis for this disease. It uses approved companion diagnostic tests to identify those patients who will respond, including HER2 immunohistochemistry tests and HER2 gene-amplification tests.

Health systems vary in their adoption of this innovative, life-extending technology and its companion diagnostic tests. Herceptin was approved for medical use in the United States in 1998 and in Europe in 2000 (European Medicines Agency 2017). Trastuzumab is now on the World Health Organization's List of Essential Medicines, the most effective and safe medicines needed in a health system (World Health Organization 2015). According to some sources, the wholesale price in the developing world is between 1800 and 1955 USD per $440 \mathrm{mg}$ vial (Management Sciences for Health 2014), already well below prices in high-income countries, but out of the reach for the poorest. Even in Australia, a 2001 cost-effectiveness analysis led to rejection for coverage; the government created a separate "Herceptin Program" to provide access for breast cancer patients (Neumann et al. 2017: 12).

Delay between approval and insurance reimbursement for trastuzumab for metastatic breast cancer ranged from 126 days in the Czech Republic to over 2000 days in Hungary and Romania and over 10 years in Slovakia, compared to less than one week in Sweden, Finland, Germany, and the Netherlands (Wait 2016: Figure 2). Moreover, even when trastuzumab is covered, patients in Eastern Europe often have to pay fully out-of-pocket for other HER2-targeted drugs such as peruzumab (Mayor 2016). In Thailand, trastuzumab was approved in September 2000, but originally only patients covered by the Civil Servants' Medical Benefit Scheme had access to the medicine free of charge; patients covered by the Social Security Scheme and Universal Coverage had to pay out of pocket for trastuzumab treatment (Ross-Degnan et al. 2015). The innovation of trastuzumab begets shortage; some patients do not have access.

However, this example also illustrates, as Deaton (2013) emphasizes, how the inequality arising from breakthrough technology often leads to later innovations to extend access. In the case of PPM, the development of biosimilars can help 
to reduce the price and improve access to this technology. Roche/Genentech's patents of Herceptin expired in 2014 in Europe, and in 2019 in the United States (Taylor 2017); in 2013, Roche/Genentech relinquished its patent right for the drug in India (NCK 2017). The first biosimilar version of the drug, developed by Biocon and Mylan, received market authorization in India in 2013, and two years later BIOCAD announced the first trastuzumab biosimilar approved by the Ministry of Health of the Russian Federation (Singhroy 2016). Many countries establish systems to try to mitigate shortage and provide access to those otherwise unable to afford the treatment, such as Australia's separate fund covering Herceptin, or Singapore's inclusion of trastuzumab in its medication assistance program.

Many other examples of PPM and its diffusion process could be given, including Erbitux (cetuximab), which targets EGFR to treat metastatic colorectal cancer, and Gleevec (imatinib), which targets the cell-surface tyrosine kinase receptor c-kit in gastrointestinal stromal tumors (Hamburg - Collins 2010). For the latter, wholesale cost in the developing world is about 1386.49 to $19,162.50$ USD a year (Frye 2015).

Shortage, for example as manifest by lack of access to life-extending immuneoncology therapies, spurs cost-reducing innovations, not only in the technologies themselves (e.g., lower-cost diagnostic tests), but also innovations in the institutions created to monitor safety and access (e.g., regulatory approval and insurance coverage decisions). For example, regional groups coordinate evidentiary standards to streamline approvals, and the European Medicines Agency has piloted adaptive licensing schemes (Wait 2016). Purchasers have set up standalone funds for innovative therapies (e.g., Italy, UK) that subsidize patient access even while the drug is under review or if denied coverage. Others have innovated with value-based pricing, managed entry agreements, and risk-sharing schemes between purchasers and manufacturers. Since these process innovations have not yet themselves been rigorously evaluated for their cost-effectiveness (given the relatively high contracting costs of establishing, monitoring, and enforcing them), it remains unclear how far they will take us in alleviating the innovation-induced shortage of personalized therapies.

Sometimes, approval and pricing criteria are not transparently based on any evaluation of benefits and costs, and the contracting discussions involve case-bycase "price negotiations, discounts or different compensation (e.g., reimbursement of new drugs and financing some other program or project in health care - device donations)", as discussed by Čatić (2016: 14) for the case of Bosnia and Herzegovina. Institutions need to evolve to guide such negotiations towards social value and clearly delineate ethical and legal parameters to avoid conflicts of interest in evaluation decisions while still promoting patient access to new therapies. 
Moreover, while many tend to think of the cost-effectiveness of a given therapy as an immutable characteristic, it is not (Berndt - Trusheim 2017). In fact, there is a strategic decision process of the innovator - the firm developing the therapy and deciding about its companion diagnostic test threshold - shaped by the "rules of the game" set by governments and/or purchasers. An additional important factor is the competitive environment, or what Kornai calls rivalry. The prices established in high-income countries like Europe and Japan as a result of this strategic decision process then dictate access for patients in other markets such as Eastern Europe and other parts of Asia where there is a lower ability and willingness to pay for these treatments.

Innovating firms can also contribute to solidarity-enhancing innovation by designing patient access arrangements to make it possible for poorer patients to receive PPM therapies despite their high price. Actually, such access programs constitute a form of price discrimination - a seller charging different customers different prices for the same good or service. As such, access programs combine social responsibility with profit maximization. In the most common form of price discrimination, a seller differentiates or separates customers into different groups, setting a different price for each group based on certain characteristics such as their willingness and ability to pay, or price elasticity. More inelastic consumers (e.g., the rich) can be charged a higher price than those in the more elastic sub-market (e.g., the poor), leading to more revenue than uniform pricing. The sub-markets must be kept separate to prevent arbitrage by enterprising consumers and their agents (such as US patients buying online drugs at prices offered in poor countries); the separation can be enforced by time, physical distance, and/or nature of use. Of course, a prerequisite for price discrimination is that the seller possesses a monopoly or at least some market power to set prices.

Pharmaceutical firms' patient assistance programs illustrate how price discrimination reduces shortage and enhances access for the poor. The firm can separate the low income patients eligible for the assistance program from the "average" patient covered by health insurance, charging the latter a price well above marginal cost. Firms may work closely with a neutral third party to identify which patients qualify for the access program. In practice, one way firms accomplish this "price" discrimination is not by stating a lower price (which would run the risk of becoming a low reference price that is then demanded by insurance companies and other patients), but rather by donating whole cycles of treatment after the patient has already purchased the initial treatment cycles. While this has the same effect as a price discount, no formal price adjustment is made; the patient buys at the regular price and then, to promote access and sales, the firm donates the rest. 


\section{CONCLUSION}

The incorporation of personalized medicine into clinical practice represents a long-term trend that interacts with demographic changes to challenge current and future generations. Longer lives and higher proportions of older people may exacerbate shortage, despite the tremendous product and service innovations that Kornai has emphasized spring from the dynamism of capitalism. The irony seems profound (Eggleston 2016): Is the good or service that we value most - health and longevity - ironically the one where we cannot enjoy the surplus economy of capitalism? Ultimately, the answer to this question depends on whether we can innovate with cost-reducing products and strategies as much as with costincreasing ones, and are resiliently persistent in our quest to balance choice with solidarity.

Cautious optimism could be warranted regarding the power of innovation to produce both "miracle drugs" and the new approaches to financing and payment that will spread their benefits more widely. Public and private sector stakeholders have to work together to enhance access while avoiding conflicts of interest (e.g., bribing regulators to cover high-price therapies even if not cost-effective). Access initiatives in low-income countries and for other vulnerable groups represent an interesting case. Patient access programs by pharmaceutical firms actually exemplify price discrimination, and thus are fully compatible with for-profit incentives. But this fact need not deny the humanity of such initiatives or their social value, as long as a balanced approach is taken to safeguard and protect public health goals.

In the health sector, dangers arise from over-emphasizing the Yin of innovation over the Yang of access, and vice versa. If we over-constrain innovation, we die needlessly early and forfeit quality of life that innovations might have enabled. If we do not distribute access to innovations equitably, we diminish our humanity, suffer backlashes from populism and distrust of science and expertise, and risk social instability, even violent conflict. ${ }^{5}$ Wisely navigating these dangerous shoals will determine whether or not our children and grandchildren have the opportunity to live healthy lives to 100 years of age.

5 Clearly, those who insist all healthcare is a "human right" do not usually mean they condone bankrupting taxpayers and eviscerating efforts to address the social determinants of health to provide access to any medical technology that provides a few extra hours of comfort; and those who want to reward innovation while insisting the poor and sick can wait for "trickle down benefits" cannot deny the ethical challenges of consigning to an early death those patients with rapidly progressing life-threatening conditions like cancer. 


\section{REFERENCES}

Arrow, K. J. (1963): Uncertainty and the Welfare Economics of Medical Care. American Economic Review, 53(5): 941-973.

Babiarz, K. S. - Eggleston, K. - Miller, G. - Zhang, Q. (2015): An Exploration of China's Mortality Decline under Mao: A Provincial Analysis, 1950-80. Population Studies, 69(1): 39-56.

Berndt, E. R. - Trusheim, M. R. (2017): The Information Pharms Race and Competitive Dynamics of Precision Medicine. Paper Presented at the National Bureau of Economic Research Conference on Economic Dimensions of Personalized and Precision Medicine, Santa Monica, CA, September, 2017.

Čatić, T. (2016): Market Access Pricing in Central and Eastern Europe: Practical Guide to Successful Reimbursement in Bosnia and Herzegovina. ISPOR Central \& Eastern Europe Network Newsletter 4(1). Https:/Www.Ispor.Org/Ceenetwork/Newsletter/2016/Guide-To-SuccessfulReimbursement-Bosnia-Herzegovina-And-Ukraine.Pdf.

Cybulski, J. S. - Clements, J. - Prakash, M. (2014): Foldscope: Origami-Based Paper Microscope. Plos One 9(6): E98781.

Chernew, M. E. - Newhouse, J. P. (2012): Health Care Spending Growth. Handbook of Health Economics, 2: 1-43.

Deaton, A. (2003): Health, Inequality, and Economic Development. Journal of Economic Literature, 41(1): 113-158.

Deaton, A. (2013): The Great Escape: Health, Wealth, and the Origins of Inequality. Princeton University Press.

Eggleston, K. (2016): Innovation, Shortage, and the Economics of Health Care Systems. In: Hámori, B. - Rosta, M. (eds): Constraints and Driving Forces in Economic Systems: Studies in Honour of János Kornai. Cambridge Scholars Publishing, pp. 15-29.

European Medicines Agency (2017): Herceptin. EMA.Europa.Eu. (Last Updated April 19, 2017, accessed September 5, 2017. http://Www.Ema.Europa.Eu/Ema/Index.Jsp?Curl=Pages/Medicines/Human/Medicines/000278/Human_Med_000818.Jsp\&Murl=Menus/Medicines/Medicines.Jsp\&Mid=WC0b01ac058001d125).

Frye, J. E. (ed.) (2015): International Drug Price Indicator Guide. MSH.Org. July 2, 2015. (Accessed September 5, 2017. http://Apps.Who.Int/Medicinedocs/Documents/S21982en/S21982en.Pdf.)

Gulácsi, L. - Orlewska, E. - Péntek, M. (2012): Health Economics and Health Technology Assessment in Central and Eastern Europe: A Dose of Reality. The European Journal of Health Economics, 13(5): 525-531. https://Link.Springer.Com/Article/10.1007\%2Fs10198-012-0411-X.

Hamburg, M. - Collins, F. (2010): The Path to Personalized Medicine. The New England Journal of Medicine, 363(4): 301-304.

Kornai, J. - Eggleston, K. (2001): Welfare, Choice and Solidarity in Transition: Reforming the Health Sector in Eastern Europe. Cambridge, UK: Cambridge University Press.

Kornai, J. (2013): Dynamism, Rivalry, and the Surplus Economy: Two Essays on the Nature of Capitalism. Oxford University Press.

Management Sciences for Health (2014): Trastuzumab. Mshpriceguide.Org., January, 2014. (Accessed September 5, 2017. http://Mshpriceguide.Org/En/Single-Drug-Information/?Dmfid=147 $1 \&$ Searchyear=2014).

Mayor, S. (2016): Differences in Availability of Cancer Drugs across Europe. The Lancet Oncology, 17(9): 1196. http://Www.Thelancet.Com/Journals/Lanonc/Article/PIIS1470-2045(16)30378-3/ Fulltext. 
NCK Pharma Solution (2017): Mylan Settles Trastuzumab Patent Litigation with Genentech and Roche. Nckpharma.Com., March 15, 2017. (Accessed September 5, 2017. https:/Nckpharma. Com/Index.Php/Mylan-Settles-Trastuzumab-Patent-Litigation-With-Genentech-And-Roche/).

Neumann, P. J. - Ganiats, Th. G. - Russell, L. B. - Sanders, G. D. - Siegel, J. E. (2017) (eds): Cost Effectiveness in Health and Medicine. Oxford University Press.

Nobelprize.Org. (2017): Youyou Tu - Facts. Nobel Media AB 2014. (Accessed: 12 Oct 2017, $<$ http://Www.Nobelprize.Org/Nobel Prizes/Medicine/Laureates/2015/Tu-Facts.Html>

Ross-Degnan, D. - Lu, Ch. Y. - Chaiyakunapruk, N. - Wagner, A. K. (2015): Policies and Programs to Facilitate Access to Targeted Cancer Therapies in Thailand. PLOS ONE (2015). http://Journals.Plos.Org/Plosone/Article?Id=10.1371/Journal.Pone.0119945.

Singhroy, D. - Love, J. (2016): Proposal for the Inclusion of Trastuzumab Emtansine (T-Dm1) in the WHO Model List of Essential Medicines for the Treatment of HER2-Positive Locally Advanced or Metastatic Breast Cancer. Knowledge Ecology International, December, 2016. (Accessed September 5, 2017. http://Www.Who.Int/Selection_Medicines/Committees/Expert/21/ Applications/S8_Trastuzumab_Emtansine.Pdf?Ua=1).

Wait, S. (2016): Access to Immuno-Oncology Therapies - European Policy Perspective. The American Journal of Managed Care, 20(2). http://Www.Ajmc.Com/Journals/Evidence-BasedOncology/2016/February-2016/Access-To-Immuno-Oncology-Therapies-European-PolicyPerspective/P-1.

World Health Organization (2015): 19th WHO Model List of Essential Medicines. WHO.Int., April, 2015. (Accessed September 5, 2017. http://Www.Who.Int/Medicines/Publications/Essentialmedicines/EML_2015_FINAL_Amended_NOV2015.Pdf?Ua=1).

Xu, Ch. (2017): Capitalism and Socialism: A Review of Kornai's Dynamism, Rivalry, and the Surplus Economy. Journal of Economic Literature, 55(1): 191-208. 